\title{
Psychiatric Comorbidity and Psychopathology of Methamphetamine Users-Are There Gender Differences?
}

\author{
Andreas G. Franke ${ }^{1,2}$ - Stefanie Neumann ${ }^{2,3,4}$ - Lisa Proebstl2,4 Felicia Kamp $^{2,4}$. \\ Laura Hager $^{2,4} \cdot$ Kirsi Manz $^{2,5} \cdot$ Daniela Krause ${ }^{2,4} \cdot$ Jochen Mutschler ${ }^{2,5} \cdot$ Gabi Koller $^{2,4}$. \\ Michael Soyka ${ }^{2,4}$
}

Accepted: 15 December 2021

(C) The Author(s) 2022

\begin{abstract}
Methamphetamine use disorder is associated with severe psychiatric symptoms and psychosocial problems. Women seem to be more affected than men. Therefore, this study examined psychiatric comorbidities and psychopathology, drug use patterns, and treatment outcomes in women addicted to methamphetamine compared to men. Data on methamphetamine-dependent inpatients were collected in two centers specialized for addiction treatment at admission (T0) and discharge (T1, after treatment for 24 weeks). Sociodemographic and clinical measures were collected with the semi-structured clinical interview I at baseline; the self-reported standardized questionnaire (SCL-90-R) was administered at admission and discharge and after 24 weeks. During the entire treatment procedure, treatment relevant aspects were monitored. Out of all 108 treatment-seeking participants (86 men, 22 women), 64 completed the study (51 men, 13 women; drop-out rate: $40.7 \%$ $(n=44))$. Methamphetamine-dependent women used other stimulants more often than men, while men used hallucinogens significantly more frequently than women. Female inpatients differed significantly from men in various sociodemographic variables (e.g., having children, single parenting) and were significantly more often affected by current $(p<0.001)$ and lifetime mental stress disorders $(p<0.001)$, as well as specific psychiatric disorders $(p<0.001)$ (e.g., posttraumatic stress disorder). At discharge, mental symptoms decreased significantly in men but not in women. Both before and after treatment, women seem to be more vulnerable to psychiatric comorbidities and psychopathologic symptoms compared to men. Although this study only provides preliminary data on gender-specific characteristics of methamphetamine-dependent patients and their treatment, it seems appropriate to discuss the development of gender-specific treatment options. Further studies in this field are needed.
\end{abstract}

Keywords Methamphetamine use disorder · Gender · Treatment · Psychopathology • Comorbidity

Andreas G. Franke and Stefanie Neumann contributed equally to this work.

Andreas G. Franke

andreas.franke@arbeitsagentur.de

Extended author information available on the last page of the article 
Methamphetamine (MA) use disorder, which has become a major global public health concern, shows a paucity of gender-specific studies (UNODC, 2019). A recent research report concluded that although men are more likely than women to use almost all types of illicit drugs (National Institute for Drug Abuse, 2020), women are just as likely to develop a substance use disorder and may be more susceptible to craving and relapse. Amphetamines have a significant risk of abuse (Soyka et al., 2017). Data indicate that especially methamphetamine seizures in the EU have increased. It is estimated that 12.3 million adults aged 15-64 years have used amphetamines at least once in their life (EMCDDA, 2020). Analysis of municipal wastewater carried out in 2019 found that mass loads of amphetamines varied considerably across Europe, with the highest levels reported in cities in the north and east of Europe. More than 20,000 clients entering specialized drug treatment in Europe in 2018 reported amphetamines as their primary drug (about 10,000 first-time clients). Apparently, amphetamines are the drugs with the smallest gender gap, although women represent only $26 \%$ of amphetamine clients. Women may be more vulnerable to the reinforcing effects of stimulants (NIDA, 2020), with estrogen possibly being a mediating factor for this increased sensitivity (Anker \& Carroll, 2011). To date, there are few studies on treatment outcomes in patients using psychostimulants (Soyka et al., 2017; Kamp et al., 2019, 2020; Simpson et al., 2016).

MA use disorder (MUD) causes significant health concerns and social problems, which may be more pronounced in women compared to men (Cohen et al., 2007; Dluzen \& Liu, 2008; Neumann et al., 2017a, b). Psychiatric disorders may also be more frequent in female MA users compared to men (Proebstl et al., 2019a).

On the one hand, previous studies have demonstrated MUD to be associated with posttraumatic stress disorder (PTSD) (Polcin et al., 2012), anxiety disorders (e.g., GlasnerEdwards et al., 2010), and depression (e.g., Dluzen \& Liu, 2008; Glasner-Edwards et al., 2009; Messina et al., 2008; Vik, 2007) as well as suicidal ideation (Hser et al., 2005; Lin et al., 2004). The reasons for MA use in women include "self-medication" of the abovementioned disorders as well as managing everyday life and suppressing nightmares (Milin et al., 2016); increase of energy and decrease of exhaustion associated with work, home care, child care, and family responsibilities (NIDA, 2020); and weight loss (Cretzmeyer et al., 2003, Brecht et al., 2004). The overall mental health state in women is influenced by work-family initiatives ( $\mathrm{Li} \&$ Wang, 2021). On the other hand, female MA users may be more affected by negative psychosocial conditions, e.g., partner violence, low economic status, and lack of a social network (Boeri et al., 2011). Furthermore, previous studies indicate that first MA use among women occurs in the early 20 s (e.g., Liu et al., 2013; Simpson et al., 2016). MA-using women were reported to have high rates of depression (Hser et al., 2005; Zweben et al., 2004, Rawson et al., 2005). Regarding further gender aspects, female MA users are characterized by having unstable (sexual) partnerships (e.g., Brecht \& Herbeck, 2014; Semple et al., 2013) and having a low educational level (Ludwig-Barron et al., 2014; Shen et al., 2012). Female and male MA users suffer from economic shortcomings and the participation in the labor market is limited, especially in female MA users (e.g., Gorman et al., 2003; Lamonica \& Boeri, 2015; Powelson et al., 2014; Rommel et al., 2015; Semple et al., 2013). Furthermore, MA-using women are at high risk for (unplanned) pregnancies due to frequent high-risk sexual behavior and are relatively young when bearing their first child (Brecht \& Herbeck, 2014; Mühlig et al., 2015). Vulnerable populations of women for methamphetamine use are sex workers and sexual minorities, homeless, psychiatric patients, suburban, or pregnant women in whom amphetamine-type stimulant use are the most commonly reported illicit drugs (Kittirattanapaiboon et al., 2017). In addition, intimate partner violence is a frequent problem in this population and weight loss is a 
reason for psychostimulant use specifically in women (Chen et al., 2014, Paulus \& Stewart, 2020).

In light of the above, a gender-sensitive treatment approach seems to be needed by creating an environment (e.g., site and staff selection, program development, content, and materials) that reflects the special needs of women (e.g., Grella et al., 2000). This is missing so far. However, to develop gender-specific treatment options, it is necessary to further explore the interrelationships between MA use and psychiatric comorbidity in female MUD patients.

Therefore, the current study examined gender differences in MUD inpatients enrolled in a 24-week treatment program in Germany using an exploratory design. It is hypothesized that women and men with MUD do not profit equally from standardized treatment programs for MUD. The aim of the study was to identify gender-associated characteristics in sociodemographics, psychiatric comorbidities, and psychopathology that are possibly relevant for developing gender-sensitive prevention and treatment strategies.

\section{Methods}

\section{Study Design}

Participants for this study were recruited from two German treatment centers for addiction (Clinic of Hochstadt, MEDIAN Clinic in Mecklenburg). Data were collected at two time points: T0 (baseline, directly after withdrawal, during the first 2 weeks of rehabilitation treatment) and $\mathrm{T} 1$ (end of rehabilitation treatment, approximately 24 weeks) (Kamp et al., 2019, 2020; Proebstl et al., 2019b, c; Soyka et al., 2017).

\section{Participants}

All participants were inpatients of one of the abovementioned treatment centers. Inclusion criteria were informed consent, diagnosis of MUD (according to ICD-10 diagnosis F15.2, mental and behavioral disorders are due to use of stimulants), and age over 18 years. Participants had to be abstinent from alcohol, MA, and other illegal substances for the entire treatment duration. Exclusion criteria included "all severe symptoms and severe disorders being currently able to influence (disrupt) measurements" (e.g., symptoms of depression, mania, psychosis, anxiety). Specifically, substance use of any kind during the whole study led to participants' exclusion and was verified by urine tests several times during the study. Furthermore, the inability to read or understand the study tests (for inclusion and testing procedure) was an exclusion criterion. All participants received compensation ( $€ 15$ by bank transfer). Urine samples and breath alcohol tests were routinely performed to ensure continuous abstinence.

\section{Treatment Concept}

Both treatment centers (Clinic of Hochstadt, MEDIAN Clinic in Mecklenburg) are experienced inpatient treatment centers and offer 6 months of treatment for patients addicted to illegal drugs (and comorbid disorders). The therapy concept in Mecklenburg represents "treatment as usual" (TAU) offering a multimodal therapy without any MA use-specific 
content (group and single settings; relapse prevention, self-reflection, development of new behavioral strategies; group therapy five times per week). The therapy concept in Hochstadt consists of three weekly conventional group therapy sessions as well, plus the additional psychoeducational group (amphetamine-type stimulant patients) once per week with an emphasis on effects of MA use in general, regarding emotions and sleep, coping strategies, relapse prevention (traps), sexuality, and use of other drugs.

\section{Measurements}

Participants completed several interviews and questionnaires (German versions) at $\mathrm{T} 0$ and T1. After consenting to the study, sociodemographic and gender-sensitive data were collected according to the "Documentation Standards III for the Evaluation of the Treatment of Dependents" (DOCU-III) (DGS, 2001). This instrument was originally developed from standards for quality assurance in the development of questionnaires for the evaluation in the field of addiction and captures all relevant sociodemographic, psychiatric, addictionspecific, and retrospective therapeutic data. The interview duration was 30 to $60 \mathrm{~min}$.

At T0, the semi-structured clinical interview for (a) current and (b) lifetime diagnoses according to axis I of the DSM-IV (SCID-I) (Wittchen et al., 1997) was performed by specially trained study staff to assess major mental disorders. In addition, patients' medical reports were examined, and diagnoses were extracted. All clinical information about any psychiatric symptoms was collected at T0, T1, and during the entire study duration by experienced clinicians of the treatment centers.

At T0 and T1, participants completed the Symptom-Check-List-90-Revised (SCL-90-R) (Derogatis \& Unger, 2010; Franke \& Derogatis, 2002). The SCL-90-R includes 90 items across nine subscales (somatization, compulsiveness, insecurity in social contact, depression, anxiety, aggressiveness, phobic anxiety, paranoid thinking, and psychoticism) and three global scales that provide measures of psychological distress: Global Severity Index (GSI), Positive Symptom Distress Index (PSDI), and the Positive Symptom Total (PST) (shown in Table 4). $T$-values from 60 to 70 assumed critical levels, and higher values (70-80) represented a high level of symptomatology.

\section{Statistical Data Analysis}

All calculations which needed only scores/data of T0 (and not T1) have been calculated based on only T0 data. Therefore, these calculations are based on $n=108$ patients. For all calculations which needed scores/data of T0 and T1 or only T1, data of $n=64$ patients have been used. This is marked several times throughout the manuscript.

The data were analyzed using SPSS 25. Descriptive data were summarized by mean (M), standard deviation (SD), median (MD), absolute ( $n$ ), and relative frequencies (\%), as appropriate. Exact Fisher's test and chi-square test were used to test for association between categorical variables of two groups (such as men and women). Means of two independent groups were compared using the $t$-test for two independent samples; means of two dependent groups (i.e., within one gender between T0 and T1) were compared using the paired $t$-test. The paired test takes into account the correlation of the measurements between the same individuals measured at two different time points. Additionally, depending on the magnitude of the variances in the two groups to be compared, the $t$-test for equal/unequal variances was used, as appropriate. Pearson correlation coefficient was reported as a measure of the correlation between two continuous variables. Repeated measures analysis of 
variance (ANOVA) was used to examine the association between two variables over time. All results are reported together with the corresponding $p$-value, where the significance level of 0.05 was used. Optionally, $95 \%$ confidence intervals (CI) were reported. All analyses are of explorative character without adjustment for multiple comparisons.

\section{Results}

\section{Sociodemographic Data}

One hundred eight participants $(n=53$ Clinic of Hochstadt, $n=55$ MEDIAN Clinic in Mecklenburg) were included in the study and completed baseline measurements (T0). The majority of these 108 patients was male (male: $n=86,77 \%$; female: $n=22,23 \%$ ), and the mean age $(\mathrm{M})$ was 31.7 years ( $\mathrm{SD}=7.7$; men: 31.6 years, women: 32.1 years). From the sample of 108 participants (T0), 59\% ( $n=64$ patients; male: 51, female: 13) completed the treatment as scheduled and passed T1, while $41 \%(n=44$ patients) dropped out (characterized by participation at T0, no participation at T1, e.g., due to early discharge because of multiple reasons). Regarding the gender of the dropped out patients (35 men (40.7\%) and 9 women (40.9\%)), there was no significant difference (exact Fisher's test: $p=1.00$ ). Participants' characteristics, such as age, marital status, education, unemployment, income, and drug use patterns, did not differ significantly between the two treatment centers (data not shown).

Regarding the obtained sociodemographic data among all patients passing T0 $(n=108)$, significant gender differences were evident in parenting. However, no appreciable specific gender characteristics were found regarding age, marital status, education, state of unemployment, or income (Table 1). Significantly more mothers among the study participants cared for their children in their own household compared to fathers $(p<0.01)$. Mothers with MUD cared for at least one child $(\mathrm{M}=1.2, \mathrm{SD}=0.9)$ in contrast to fathers, who cared for less than one child $(\mathrm{M}=0.3, \mathrm{SD}=0.7)$. Of note, seven mothers $(38.9 \%)$ did not care for (all) of their children in their own household. Among single individuals, women cared

Table 1 Study population's sociodemographics at T0 ( $n=108$; men: $n=86$; women: $n=22)$

\begin{tabular}{|c|c|c|c|c|c|}
\hline & \multicolumn{2}{|l|}{ Men } & \multicolumn{2}{|l|}{ Women } & \multirow[b]{2}{*}{$p$} \\
\hline & $n / \mathrm{M}$ & $\% / S D$ & $N / \mathrm{M}$ & $\% / \mathrm{SD}$ & \\
\hline Age in years & 31.6 & 8.1 & 32.1 & 6.3 & NS \\
\hline Education $\leq 9$ years & 60 & 72.3 & 13 & 61.9 & NS \\
\hline Single status & 46 & 55.4 & 8 & 38.1 & NS \\
\hline Unemployed & 73 & 93.6 & 16 & 88.9 & NS \\
\hline In weeks & 82.4 & 142.2 & 96.7 & 120.5 & NS \\
\hline Have child(ren) & 40 & 48.2 & 18 & 85.7 & $<.001$ \\
\hline Single parenting & 2 & 2.4 & 9 & 52.9 & $<.001$ \\
\hline Income (net) per month in $€$ & 836.51 & 1.025 .54 & 1.075 .00 & 1.344 .82 & NS \\
\hline Illegal income & 7 & 8.6 & 1 & 5.0 & .050 \\
\hline Other/not specific income & 8 & 9.9 & 6 & 30.0 & .030 \\
\hline
\end{tabular}

$M$, mean; $S D$, standard deviation; $N S$, not significant 
at least for one child $(\mathrm{M}=1.4, \mathrm{SD}=0.8)$ in contrast to men $(\mathrm{M}=0.5, \mathrm{SD}=0.9, p=0.01)$. Regardless of marital status, significantly more mothers performed "single parenting" (Table 1). Age differences did not exist between male and female single parents $(p=0.69)$.

There was no significant difference between women and men in terms of their total length of unemployment (over the lifetime). However, at the time of treatment admission, women exhibited significantly longer (twice) ( $\mathrm{MD}=52$ weeks) unemployment compared to men ( $M D=26$ weeks). The duration of unemployment and the number of children were not associated $(r=0.2, p=0.57)$.

\section{Substance Use Patterns}

\section{Comparison Between Male and Female Participants}

Among all 108 patients, MUD men and women did not statistically differ in their age of first MA use $(p=0.97)$ nor in the onset of regular MA use $(p=0.92)$. Regarding additional substance use, women significantly more often used other stimulants $(p=0.049)$; in contrast, men significantly more often used hallucinogens $(p=0.050)$. Moreover, MUD women differed significantly from men in terms of last MA use before treatment admission, exhibiting a longer time period (Table 2).

\section{Changes Within the Gender Cohorts}

In only the female cohort, a later onset of regular MA use was correlated with a low monthly income (women: $r=-0.5, p=0.03$, men: $r=-0.1, p=0.61$ ). Furthermore, only in women significant correlations for age of first MA use (women: $r=0.4, p=0.05$; men: $r=0.0, p=0.72$ ) and the onset of regular use with treatment duration were demonstrated (women: $r=0.5, p=0.04$; men: $r=0.0, p=0.76$ ). The later the start of MA use, the longer the treatment duration was.

\section{Treatment Outcomes}

\section{Comparison Between Male and Female Participants}

Of all 108 patients, 44 dropped out of the study before reaching T1 (men: $n=35$; women: $n=9$ ). The drop-out rate did not differ between men and women (exact Fisher's test: $p>0.99$ ). Similarly, the remaining 64 patients (men: $n=51$; women: $n=13$ ) did not show any gender differences (exact Fisher's test: $p=0.99$ ). Likewise, concerning treatment duration in these 64 patients, there were no gender differences in marital status, number of children, or child-caring in the participant's own household.

\section{Changes Within the Gender Cohorts}

Furthermore, single women used MA over 14.1 years $(\mathrm{SD}=6)$ and women living in partnership for only $11.4(\mathrm{SD}=6.5)$ years. Although this difference was not statistically significant $(p=0.71)$, it seems to be noteworthy. However, regardless of marital status, the status of being a mother $(p=0.32)$ or caring for children in one's own/maternal household 
Table 2 Methamphetamine and drug use at T0 $(n=108$; men: $n=86$; women: $n=22)$

\begin{tabular}{|c|c|c|c|c|c|}
\hline & \multicolumn{2}{|l|}{ Men } & \multicolumn{2}{|c|}{ Women } & \multirow[b]{2}{*}{$p$} \\
\hline & $n / \mathrm{M}$ & $\% / S D$ & $n / \mathrm{M}$ & $\% / \mathrm{SD}$ & \\
\hline Methamphetamine as the sole drug & 46 & 53.5 & 14 & 63.5 & NS \\
\hline \multicolumn{6}{|l|}{ Application } \\
\hline Oral & 2 & 2.5 & 1 & 5.3 & \multirow[t]{4}{*}{ NS } \\
\hline Snort & 63 & 78.8 & 15 & 78.9 & \\
\hline Inject & 5 & 6.3 & 2 & 10.5 & \\
\hline Smoke & 10 & 12.5 & 1 & 5.3 & \\
\hline Use in years & 11.3 & 5.9 & 12.4 & 6.3 & NS \\
\hline Age first in years & 19.6 & 6.14 & 19.6 & 6.95 & NS \\
\hline Age onset regular use in years & 20.8 & 6.18 & 20.9 & 6.77 & NS \\
\hline Last use in days & 263.4 & 433.40 & 115.6 & 148.91 & .013 \\
\hline Days of use last 30 days & 4.0 & 8.58 & 5.6 & 11.05 & NS \\
\hline Days of use last 6 months & 59,6 & 72.78 & 64.2 & 72.78 & NS \\
\hline \multicolumn{6}{|l|}{ Use of other drugs } \\
\hline Tobacco & 78 & 96.0 & 18 & 90.0 & NS \\
\hline Alcohol & 80 & 98.8 & 20 & 100.0 & NS \\
\hline Cannabis & 77 & 95.1 & 19 & 95.0 & NS \\
\hline Opioids & 30 & 37.0 & 5 & 25.0 & NS \\
\hline Calming psychotropic drugs & 19 & 23.8 & 4 & 20.0 & NS \\
\hline Cocaine & 55 & 67.1 & 13 & 65.0 & NS \\
\hline Ecstasy & 54 & 65.9 & 13 & 65.0 & NS \\
\hline Other stimulants & 5 & 6.1 & 4 & 20.0 & .049 \\
\hline Hallucinogens & 36 & 43.9 & 4 & 20.0 & .050 \\
\hline Other inhalants & 11 & 13.4 & 1 & 5.0 & NS \\
\hline Other substances & 17 & 22.0 & 2 & 10.0 & NS \\
\hline
\end{tabular}

$M$, mean; $S D$, standard deviation; $N S$, not significant

( $p=0.88)$ had no significant effect on the duration of MA use, which also held for men/ fathers.

\section{Psychiatric Comorbidities and Psychopathology}

Regarding further aspects associated with MA use among all 108 patients (men: $n=86$; women: $n=22$ ), men had been arrested significantly more often than women (Table 3 ). The medical history of the study participants revealed that significantly more women than men suffered from psychiatric disorders (without SUD) at the time of treatment admission $(p=0.012)$. According to SCID-I, women were more often diagnosed as having PTSD $(p<0.01)$ and mental stress disorders (current $p<0.01$, lifetime $p<0.01)$ than men. Even at treatment discharge, women had significantly more psychiatric disorders and SUDs compared to men $(p<0.01)$ (Table 3).

Since completion of the SCL-90-R questionnaire was voluntary, at T0, $n=16$ inpatients (11 men, 5 women) did not provide any information (reasons were not recorded). In the SCL-90-R $(n=92)$, at treatment admission, 15 men (20\%) and 11 women $(64.7 \%)$ achieved 
Table 3 Process of treatment and pre-therapeutic mental symptomology among all patients passing T0 ( $n=108$; man: $n=86$; women: $n=22)$

\begin{tabular}{|c|c|c|c|c|c|}
\hline & \multicolumn{2}{|l|}{ Men } & \multicolumn{2}{|c|}{ Women } & \multirow[b]{2}{*}{$p$} \\
\hline & $n / \mathrm{M}$ & $\% / \mathrm{SD}$ & $n / \mathrm{M}$ & $\% / \mathrm{SD}$ & \\
\hline Number of treatments for SUD & 1.03 & 2.08 & 0.40 & 0.75 & NS \\
\hline Duration of the current treatment (days) & 145.5 & 69.9 & 171.0 & 69.5 & NS \\
\hline Premature discharge from current treatment & 35 & 40.7 & 9 & 40.9 & NS \\
\hline \multicolumn{6}{|l|}{ Vulnerability factors } \\
\hline Ever had suicide thoughts & 13 & 15.9 & 7 & 35.0 & NS \\
\hline Ever suicide attempted & 14 & 17.1 & 5 & 25.0 & NS \\
\hline Ever arrested & 57 & 70.4 & 5 & 25.0 & $<.001$ \\
\hline \multicolumn{6}{|l|}{ At treatment admission } \\
\hline Mean of psychiatric disorders without SUD & 0.45 & 0.73 & 0.91 & 0.81 & .012 \\
\hline Mean of other SUD & 2.26 & 1,23 & 2.00 & 1.16 & NS \\
\hline PTSD F43.0 (ICD-10) & 3 & 3.5 & 11 & 50.0 & $<.001$ \\
\hline \multicolumn{6}{|l|}{ Mental stress disorder (SCID-I) } \\
\hline Current & 3 & 3.9 & 8 & 47.1 & $<.001$ \\
\hline Lifetime & 4 & 5.3 & 7 & 41.2 & $<.001$ \\
\hline Mental stress (DOCU-III) ${ }^{\mathrm{a}}$ & 0.85 & 1.42 & 2.40 & 1.73 & $<.001$ \\
\hline \multicolumn{6}{|l|}{ At treatment discharge } \\
\hline Mean of psychiatric disorders without SUD & 0.48 & 0.73 & 1.36 & 1.18 & $<.001$ \\
\hline Mean of other SUD & 2.31 & 1.05 & 1.45 & 1.06 & .001 \\
\hline PTSD F43.0 (ICD-10) & 7 & 8.2 & 9 & 40.9 & $<.001$ \\
\hline
\end{tabular}

$S U D$, substance use disorder; $P T S D$, posttraumatic stress disorder; $S C I D-I$, structured clinical interview for DSM-IV Axis I; DOCU-III, Documentation Standards III for the Evaluation of the Treatment of Depend-

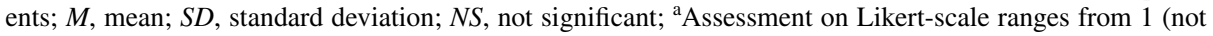
stressed) to 5 (severe stressed)

a score $\geq 60$ in the Global Severity Index (GSI), and women reached significantly higher scores than men in all scales (Table 4$)$. Merely $4 \%$ of men $(n=3)$ but $23.5 \%$ of women $(n=4)$ had a GSI $\geq 70$ (Figs. 1 and 2). Thus, the variable "gender" had a significant effect on GSI values $(p<0.01)$. Within the female cohort, the value of 60 was exceeded for GSI and psychoticism at T0 and for compulsiveness at T1. Of note, contrary to men, the maximum value of 80 was reached for almost all scales for some women (Table 4).

Women and men with GSI $\geq 60$ showed a similar treatment duration $(p=0.10)$. Having children $(p=0.83)$ or caring for a child in one's own household did not affect GSI values $(p=0.25)$.

In the group of women diagnosed with PTSD, $90 \%(n=9)$ had a high GSI $(\mathrm{M}=66$; $\mathrm{SD}=8.7 ; p=0.02)$. However, in contrast to men without PTSD diagnosis $(n=74, \mathrm{M}=53$, $\mathrm{SD}=9.4)$, women without PTSD diagnosis showed high GSI values $(n=8, \mathrm{M}=64.6$, $\mathrm{SD}=10.3)$. This gender difference was statistically significant $(p<0.01)$. Moreover, at treatment admission, half of women with GSI $\geq 70$ had no PTSD $(n=2, \mathrm{M}=79, \mathrm{SD}=1.4)$.

At treatment discharge, patients tended to show reduced scores in all scales and variables. However, only men reached significantly lower scores in all scales, with the exception of aggression (Table 4). Women only achieved significantly lower levels of compulsiveness and psychoticism. At treatment discharge, there were no longer 


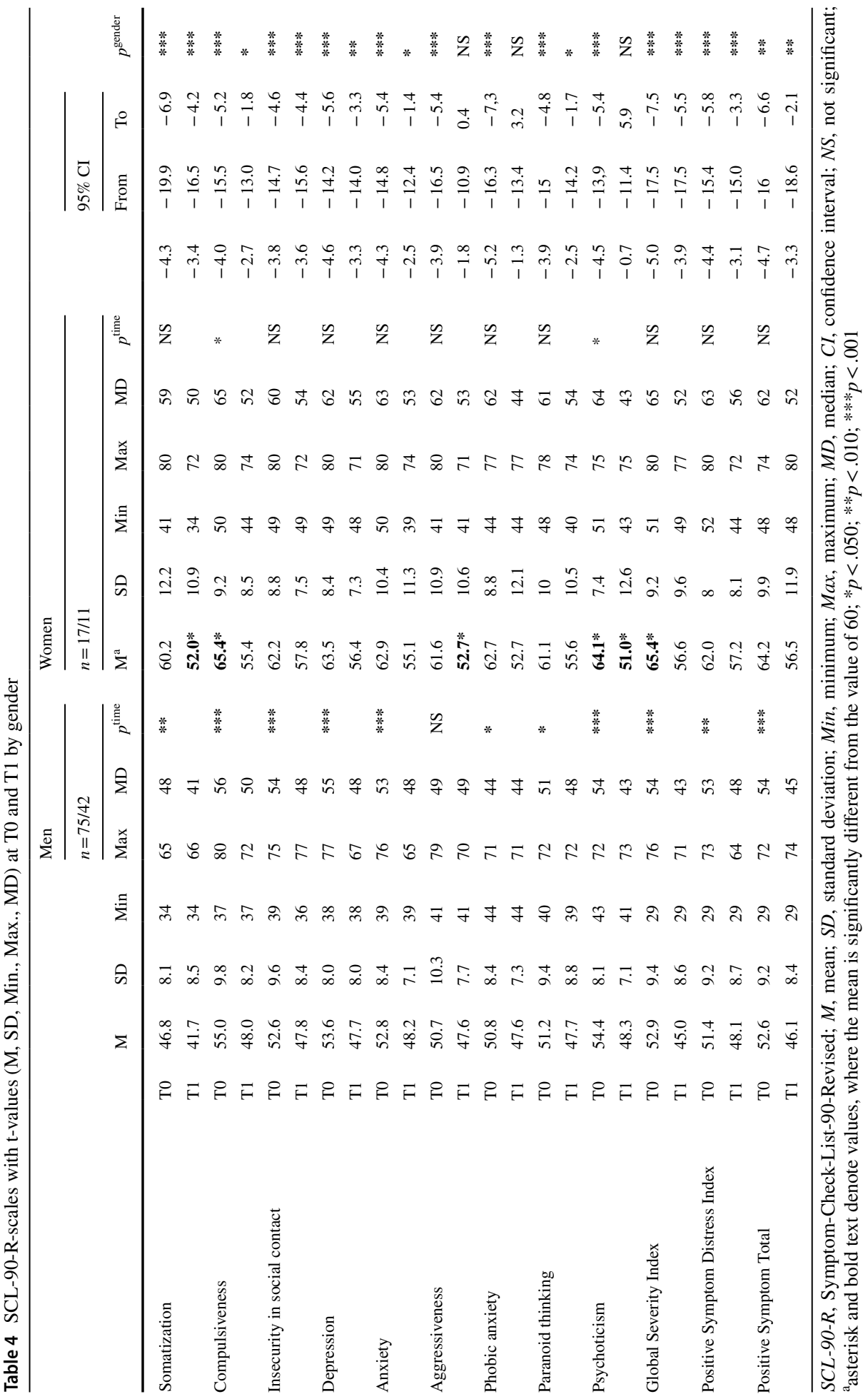


any significant gender differences in the scales of aggression, phobia, or psychoticism (Table 4). The factor "gender" had no significant effect on psychiatric symptomatology between $\mathrm{T} 0$ and $\mathrm{T} 1$ at any scale.

\section{Discussion}

The present study examined gender differences and longitudinal changes in psychiatric symptomatology in MUD inpatients over a 24-week inpatient treatment. Significant gender differences with respect to sociodemographic characteristics and comorbid psychiatric disorders were found. Our study indicates women with MUD are more often affected by mental disorders and psychiatric comorbidities (e.g., PTSD) than men. At treatment admission, female MUD inpatients exhibited significantly more non-addiction-related psychiatric comorbidities compared to men, which has been previously demonstrated in multiple studies (e.g., Brecht \& Herbeck, 2014; Glasner-Edwards et al., 2010; Salo et al., 2011; Zweben et al., 2004). In the present study, the number of individuals with PTSD at treatment admission was significantly higher in women than in men. The finding that half of the women suffered from PTSD is in line with the prevalence estimates of PTSD among MA-dependent women in another study (Polcin et al., 2012). Women also reached high levels of psychological distress across almost all domains of the SCL90-R. However, the study by John et al. (2001) with stimulant-dependent patients, which did not perform separate analyses of men and women, found high values only in psychoticism, paranoid thinking, and aggressiveness that were supposed to be gender-neutral. Furthermore, Simpson et al. (2016) did not identify significant gender differences and only slightly higher rates of "insecurity in social contact" among women. Regardless of a PTSD diagnosis, women showed higher scores in all SCL-90-R subscales than men with the highest differences regarding GSI, compulsiveness, and psychoticism. Beyond that, the question of whether these results are based on being a "prudent user" or a "self-medicator" (Klee, 1997) cannot be conclusively clarified.

Regarding sociodemographic characteristics and patterns of MA use, study results indicate fractional gender differences. These findings are in line with previous studies (e.g., Brecht et al., 2004). Female-specific characteristics regarding parenting and especially "single parenting" reflect data of single maternity in Germany (German Federal Office of Statistics, 2018). Study results from Cook et al. (2009) confirm that single mothers have a higher risk of substance abuse compared to mothers in partnerships. Wouldes et al. (2013) found similar results among MA-dependent women. Determining reasons for female MA use could involve the transition into maternity (CarboneLopez \& Miller, 2012) and parental stress, primarily in conjunction with prenatal MA use (Liles et al., 2012). However, the present study did not focus on prenatal drug use. In this study, women were in their early $30 \mathrm{~s}$, used MA for approximately 12 years, and tended to have a lower number of inpatient treatments. Dyba et al. (2019) described parenting of MA-abstinent outpatients as challenging, inconsistent, impulsive, and emotionally negligent. In single mothers, overburdening of educational responsibility plays a decisive role (Klein et al., 2016). In our investigation, parenting and child care were not associated with MA use duration or GSI score. However, mental stress could be based on missing custody, because, in seven cases, mothers did not care for (all) their children in their household. However, this aspect was not investigated in the present study. Furthermore, long-term unemployment among the women in this study may be 


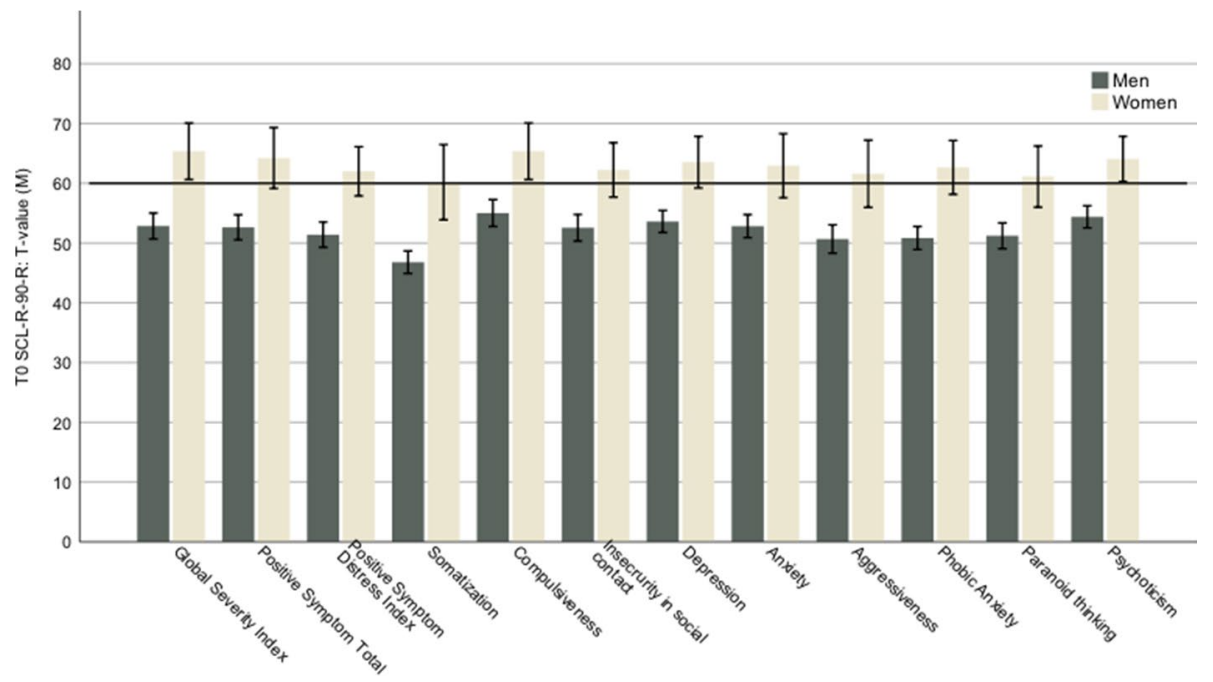

Fig. 1 SCL-90-R T-values (M with two times SD, 95\% error level) at T0 by gender

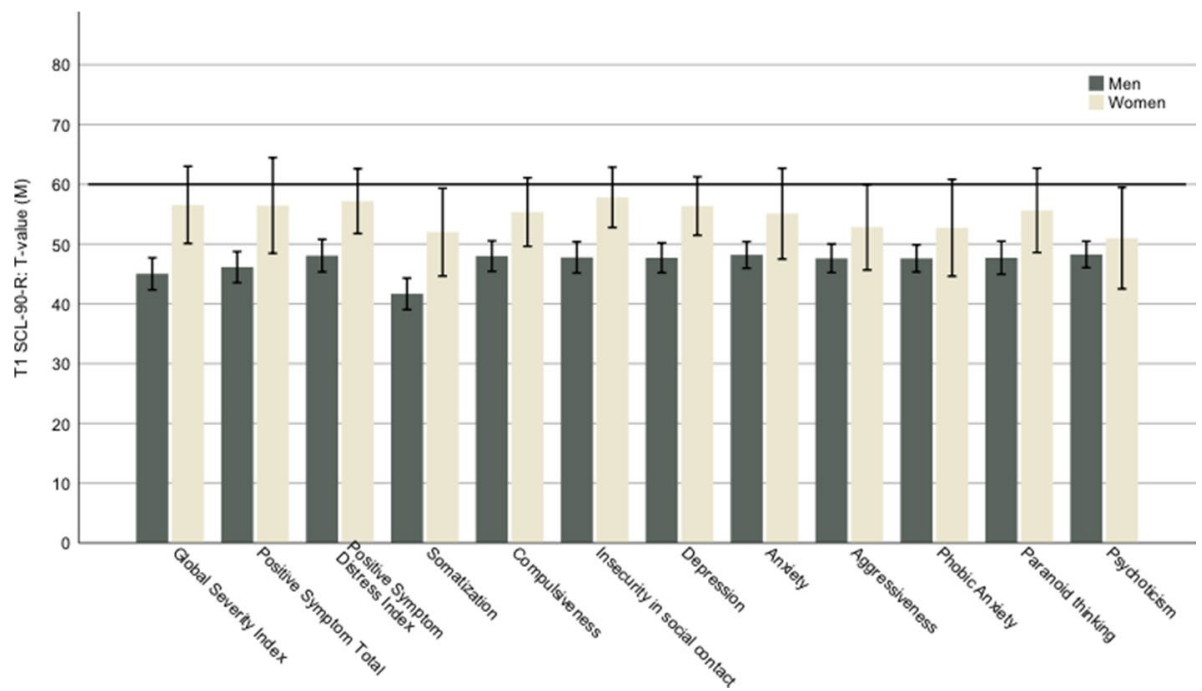

Fig. 2 SCL-90-R T-values (M with two times SD, 95\% error level) at T1 by gender

a result of the inadequately managed transition from school to the labor market caused by MUD; this assumption has been proved for somatic and mental health problems in general (Bartley, 1994; Murphy \& Athanasou, 1999; Voss et al., 2020). In Germany, the 
number of unemployed inpatients with stimulant dependence has increased during the last years (Kipke et al., 2015). Therefore, overburdened parenting and socially unstable conditions due to unemployment in interaction with SUD should be relevant indices for treatment.

Regarding drop-outs, men and women showed the same retention rates. More than half of subjects completed inpatient treatment after at least 24 weeks, which is equivalent to the current treatment drop-out rate of over $30 \%$ in individuals with stimulant use disorders (Minozzi et al., 2016). In the present study, women terminated MA use shortly before treatment. This fact has to be considered gender independent (Glasner-Edwards et al. (2009). Among MA-dependent women, Hillhouse et al. (2007) reported a period of brief abstinence directly prior to treatment admission with reduced psychopathology; these findings are in line with the present study results. Regarding patients without mental disorders, McMaster (2013) indicated that even if MA-exposed women knew about the need for treatment and often showed the motivation for immediate treatment, there were still barriers to access: These barriers include "insufficient" treatment options (quantitative, topographic), as well as "mental barriers." Abdul-Khabir et al. (2014) attributed this phenomenon of substance use among pregnant MA users to the drug use itself, which results in a late or "no help" situation. Hence, the female-specific findings raise the following issues: (a) childcare during treatment and (b) treatment utilization being inhibited by the stigmatization of drug dependence and additional psychiatric disorders (Bairan et al., 2014; Semple et al., 2007). Gender-responsive treatment was found to reduce PTSD and related symptoms in comparison to non-gender responsive treatment in a cohort of female offenders $(71 \%$ using methamphetamine), showing promising results for gender-specific treatment regimes (Messina et al., 2014).

At the time of discharge, psychiatric symptoms had decreased significantly only in men and persisted in women who were more severely affected. Women differed significantly from men in almost all scales, except for aggression, phobic anxiety, and psychoticism. Similar findings were reported in the review by Huhn et al. (2019) on treatment outcomes among women with opioid use disorders.

Therefore, the therapeutic relevance of mental disorders and psychiatric comorbidity (e.g., PTSD) in female MUD inpatients is apparent. The literature on the treatment of female MUD is surprisingly limited (NIDA, 2020). Najavits and Hien (2013) recommend stabilization and psychoeducation, as well as teaching coping skills, as part of the treatment procedure. According to the authors, this can be achieved using integrative cognitive behavioral therapy. Furthermore, for women, Rade et al. (2015) indicated that being treated by a psychiatrist in general increased the likelihood of later use of a SUD-specific treatment.

Beyond that, with respect to psychosocial characteristics of female MUD users, this study confirms previous results of non-MUD treatment groups. The apparent question remains if there is a need to develop women sensitive treatment programs or even "womenonly" treatment programs/groups (e.g., Ashley et al., 2003; Evans et al., 2013; Greenfield et al., 2007; Grella et al., 1999; Niv \& Hser, 2007; Prendergast et al., 2006; Sun et al., 2006). According to the aforementioned literature, there may be good reasons to at least integrate gender-sensitive aspects in existing MUD treatment programs.

There are a number of limitations to this study. The major limitation is the study population with a relatively small proportion of women and the unequal distribution of men and women at T0 and T1, which could influence the overall power of the tests (Rusticus \& Lovato, 2014). On the one hand, this has to be considered as a weakness with a limitation of generalizability of the data; on the other hand, the strength of the study is the 
high standard of inclusion and exclusion criteria leading to the limited number of suitable patients meeting all inclusion and exclusion criteria. However, underrepresentation of women in inpatient treatment for stimulants dependence with a ratio of 4:1 (Dauber et al., 2018) was also confirmed in other studies with a correspondingly low female population (Malta et al., 2019; Querengässer \& Traub, 2020), as well as an underrepresentation of studies including women or elaborating female-specific aspects. Beyond that, a further limiting aspect is that neither patients' medications nor individual motives for drug use were considered. Future studies should include these aspects and should focus on the interrelationship of MUD and especially PTSD (prevalence, severity, trigger, therapeutic measures, etc.). Taken together, the present study raised questions about the extent to which mental disorders and PTSD interact with different modes of treatment.

Due to the small initial sample size of 108 patients together with the drop-out rate of $41 \%(n=44)$, analyses were performed with the highest number of patients possible: data from baseline T0 were therefore presented for all 108 patients and data from T1 for 64 patients, who did not drop out during the treatment.

As in every clinical trial, the duration of the study is a primary limiting factor leading to a drop-out. However, the retention rate in the present study was not higher than in other studies enrolling patients with MA use disorder (Brecht et al., 2005; Maglione et al., 2000).

The study protocol required the exclusion of individuals with "all severe symptoms and severe disorders being able to influence (disrupt) measurements" (e.g., symptoms of depression, mania, psychosis, anxiety)." This means that all individuals with psychotic symptoms were excluded. Although numerous patients with substance use disorders are suffering from psychosis (Hunt et al., 2018), these patients were excluded to ensure high quality of data because of cognitive decline in psychotic patients (Bortolato et al., 2015; Donoghue \& Doody, 2012).

As described, there were different therapeutic approaches in both clinics (Mecklenburg $=$ TAU/controls; Hochstadt $=$ specialized treatment procedure $)$. This led to expectable differences regarding therapeutic outcomes (Kamp et al., 2019, 2020; Proebstl et al., 2019c). In this context, it cannot be ruled out that this led to certain differences regarding the gender-sensitive questions of this paper. However, there were no significant gender differences regarding treatment completion (Mecklenburg: men $n=27 /$ women $n=8$; Hochstadt: men $n=24 /$ women $n=5 ; p=0.76$ ). Therefore, bias due to different treatment regimes seems unlikely. Moreover, a substantial part of the calculations is based on T0, when no therapeutic effect took place.

During the data analyses, no correction for multiple testing, such as the Bonferroni correction, was considered. The non-confirmatory study design was chosen to explore a wide range of possible associations between SUD and MUD and gender. The results are compared to existing data and used for suggestions for a gender-specific treatment approach.

\section{Conclusions}

This study addressed gender differences in treatment-seeking MUD inpatients and demonstrates a significant female vulnerability, especially for comorbid psychiatric disorders. The findings and clinical outcome of the present study suggest the necessity of a gendersensitive treatment concept for MUD patients.

Acknowledgements Proofreading was done by the American Journal Experts (AJE). 
Author Contribution Michael Soyka designed the research study. Stefanie Neumann performed the research with the inpatients. Stefanie Neumann, Lisa Proebstl, and Felicia Kamp analyzed and calculated the raised data. Kirsi Manz did the final calculations and supervision of all results. Andreas G. Franke, Lisa Proebstl, Felicia Kamp, Daniela Krause, Laura Hager, Jochen Mutschler, Gabriele Koller, and Michael Soyka provided assistance with data raising. All authors interpreted the data and wrote the manuscript and read and approved the manuscript.

Funding Open Access funding enabled and organized by Projekt DEAL. The present study "Evaluation of a stationary model project (MATRIX, Indicative Group ATS) for 'Crystal'-user" was funded by the German federal ministry of health (ZMVI1-2516DSM216). The funding source did not influence study design, data collection, analysis or interpretation of data as well as writing content of the manuscript.

\section{Declarations}

Informed Consent/Ethics Approval All procedures followed were in accordance with the ethical standards of the responsible committee on human experimentation (institutional and national) and with the Helsinki Declaration of 1975, as revised in 2000 (5). Informed consent was obtained from all patients for being included in the study. The Ethics Committee of the LMU Munich approved the study protocol following the Declaration of Helsinki (1975).

Conflict of Interest The authors declare no competing interests.

Open Access This article is licensed under a Creative Commons Attribution 4.0 International License, which permits use, sharing, adaptation, distribution and reproduction in any medium or format, as long as you give appropriate credit to the original author(s) and the source, provide a link to the Creative Commons licence, and indicate if changes were made. The images or other third party material in this article are included in the article's Creative Commons licence, unless indicated otherwise in a credit line to the material. If material is not included in the article's Creative Commons licence and your intended use is not permitted by statutory regulation or exceeds the permitted use, you will need to obtain permission directly from the copyright holder. To view a copy of this licence, visit http://creativecommons.org/licenses/by/4.0/.

\section{References}

Abdul-Khabir, W., Hall, T., Swanson, A. N., \& Shoptaw, S. (2014). Intimate partner violence and reproductive health among methamphetamine-using women in Los Angeles: A qualitative pilot study. Journal of Psychoactive Drugs, 46(4), 310-316. https://doi.org/10.1080/02791072.2014.934978

Anker, J. J., \& Carroll, M. E. (2011). Females are more vulnerable to drug abuse than males: evidence from preclinical studies and the role of ovarian hormones. Current Topics in Behavioral Neurosciences, 8 , 73-96. https://doi.org/10.1007/7854_2010_93

Ashley, O. S., Marsden, M. E., \& Brady, T. M. (2003). Effectiveness of substance abuse treatment programming for women: A review. American Journal of Drug and Alcohol Abuse, 29(1), 19-53.

Bairan, A., Boeri, M., \& Morian, J. (2014). Methamphetamine use among suburban women: Implications for nurse practitioners. Journal of the American Association of Nurse Practitioners, 26(11), 620-628.

Bartley, M. (1994). Unemployment and ill health: Understanding the relationship. Journal of Epidemiology \& Community Health, 48(4), 333-337.

Boeri, M. W., Tyndall, B. D., \& Woodall, D. R. (2011). Suburban poverty: Barriers to services and injury prevention among marginalized women who use methamphetamine. The Western Journal of Emergency Medicine, 12(3), 284-292.

Bortolato, B., Miskowiak, K. W., Köhler, C. A., Vieta, E., \& Carvalho, A. F. (2015). Cognitive dysfunction in bipolar disorder and schizophrenia: A systematic review of meta-analyses. Neuropsychiatric Disease and Treatment, 11, 3111.

Brecht, M. L., Greenwell, L., \& Anglin, M. D. (2005). Methamphetamine treatment: Trends and predictors of retention and completion in a large state treatment system (1992-2002). Journal of Substance Abuse Treatment, 29(4), 295-306.

Brecht, M. L., \& Herbeck, D. M. (2014). Pregnancy and fetal loss reported by methamphetamine-using women. Subst Abuse, 8, 25-33. https://doi.org/10.4137/SART.S14125 
Brecht, M. L., O’Brien, A., von Mayrhauser, C., \& Anglin, M. D. (2004). Methamphetamine use behaviors and gender differences. Addictive Behaviors, 29(1), 89-106.

Carbone-Lopez, K., \& Miller, J. (2012). Precocious role entry as a mediating factor in women's methamphetamine use: Implications for life-course and pathways research. Criminology, 50(1), 187-220.

Chen, L. Y., Strain, E. C., Alexandre, P. K., Alexander, G. C., Mojtabai, R., \& Martins, S. S. (2014). Correlates of nonmedical use of stimulants and methamphetamine use in a national sample. Addictive Behaviors, 39(5), 829-836. https://doi.org/10.1016/j.addbeh.2014.01.018

Cohen, J. B., Greenberg, R., Uri, J., Halpin, M., \& Zweben, J. E. (2007). Women with methamphetamine dependence: Research on etiology and treatment. J Psychoactive Drugs, Suppl 4, 347-351.

Cook, J. A., Mock, L. O., Jonikas, J. A., Burke-Miller, J. K., Carter, T. M., Taylor, A., . . Gruenenfelder, D. (2009). Prevalence of psychiatric and substance use disorders among single mothers nearing lifetime welfare eligibility limits. Archives of general psychiatry, 66(3), 249-258.

Cretzmeyer, M., Sarrazin, M. V., Huber, D. L., Block, R. I., \& Hall, J. A. (2003). Treatment of methamphetamine abuse: research findings and clinical directions. Journal of Substance Abuse Treatment, 24(3), 267-277. https://doi.org/10.1016/s0740-5472(03)00028-X

Dauber, H., Specht, S., Künzel, J., \& Braun, B. (2018). Suchthilfe in Deutschland 2017. Jahresbericht der deutschen Suchthilfestatistik. München: IFT Institut für Therapieforschung.

Derogatis, L. R., \& Unger, R. (2010). Symptom checklist-90-revised. The Corsini encyclopedia of psychology, 1-2.

Deutsche Gesellschaft für Suchtforschung. (2001). Dokumentationsstandards III für die Evaluation der Behandlung von Abhängigen. Sucht, 47(8), 3-94.

Dluzen, D. E., \& Liu, B. (2008). Gender differences in methamphetamine use and responses: A review. Gender Medicine, 5(1), 24-35.

Donoghue, K., \& Doody, G. A. (2012). Effect of illegal substance use on cognitive function in individuals with a psychotic disorder, a review and meta-analysis. Neuropsychology, 26(6), 785.

Dyba, J., Moesgen, D., Klein, M., \& Leyendecker, B. (2019). Methamphetamine use in German families: Parental substance use, parent-child interaction and risks for children involved. Substance Use \& Misuse, 54(4), 583-591.

European Monitoring Centre for Drugs and Drug Addiction. (2020). European Drug Report 2020: Trends and Developments, Publications Office of the European Union.

Evans, E., Li, L., Pierce, J., \& Hser, Y.-I. (2013). Explaining long-term outcomes among drug dependent mothers treated in women-only versus mixed-gender programs. Journal of Substance Abuse Treatment, 45(3), 293-301.

Franke, G. H., \& Derogatis, L. R. (2002). Symptom-Checkliste von LR Derogatis: SCL-90-R; deutsche Version: Beltz Test.

German Federal Office of Statistics. (2018). Statistical Yearbook 2018. German Federal Office of Statistics.

Glasner-Edwards, S., Marinelli-Casey, P., Hillhouse, M., Ang, A., Mooney, L. J., \& Rawson, R. (2009). Depression among methamphetamine users: Association with outcomes from the Methamphetamine Treatment Project at 3-year follow-up. The Journal of Nervous and Mental Disease, 197(4), 225.

Glasner-Edwards, S., Mooney, L. J., Marinelli-Casey, P., Hillhouse, M., Ang, A., \& Rawson, R. (2010). Anxiety disorders among methamphetamine dependent adults: Association with post-treatment functioning. The American Journal on Addictions, 19(5), 385-390.

Gorman, E. M., Clark, C. W., Nelson, K. R., Applegate, T., Amato, E., \& Scrol, A. (2003). A community social work study of methamphetamine use among women: Implications for social work practice, education and research. Journal of Social Work Practice in the Addictions, 3(3), 41-62.

Greenfield, S. F., Brooks, A. J., Gordon, S. M., Green, C. A., Kropp, F., McHugh, R. K., . . Miele, G. M. (2007). Substance abuse treatment entry, retention, and outcome in women: A review of the literature. Drug and alcohol dependence, 86(1), 1-21.

Grella, C. E., Joshi, V., \& Hser, Y.-I. (2000). Program variation in treatment outcomes among women in residential drug treatment. Evaluation Review, 24(4), 364-383.

Grella, C. E., Polinsky, M. L., Hser, Y.-I., \& Perry, S. M. (1999). Characteristics of women-only and mixedgender drug abuse treatment programs. Journal of Substance Abuse Treatment, 17(1-2), 37-44.

Hillhouse, M. P., Marinelli-Casey, P., Gonzales, R., Ang, A., Rawson, R. A., \& Authors, M. T. P. C. (2007). Predicting in-treatment performance and post-treatment outcomes in methamphetamine users. Addiction, 102, 84-95.

Hser, Y. I., Evans, E., \& Huang, Y. C. (2005). Treatment outcomes among women and men methamphetamine abusers in California. Journal of Substance Abuse Treatment, 28(1), 77-85. https://doi.org/10. 1016/j.jsat.2004.10.009

Huhn, A. S., Berry, M. S., \& Dunn, K. E. (2019). Sex-based differences in treatment outcomes for persons with opioid use disorder. The American Journal on Addictions. https://doi.org/10.1111/ajad.12921 
Hunt, G. E., Large, M. M., Cleary, M., Lai, H. M. X., \& Saunders, J. B. (2018). Prevalence of comorbid substance use in schizophrenia spectrum disorders in community and clinical settings, 1990-2017: Systematic review and meta-analysis. Drug and Alcohol Dependence, 191, 234-258.

John, D., Kwiatkowski, C. F., \& Booth, R. E. (2001). Differences among out-of-treatment drug injectors who use stimulants only, opiates only or both: Implications for treatment entry. Drug and Alcohol Dependence, 64(2), 165-172.

Kamp, F., Hager, L., Proebstl, L., Schreiber, A., Riebschläger, M., Neumann, S., . . . Pogarell, O. (2020). 12-And 18-month follow-up after residential treatment of methamphetamine dependence: Influence of treatment drop-out and different treatment concepts. Journal of Psychiatric Research, 129, 103-110. https://doi.org/10.1016/j.jpsychires.2020.05.029

Kamp, F., Proebstl, L., Hager, L., Schreiber, A., Riebschläger, M., Neumann, S., . . . Soyka, M. (2019). Effectiveness of methamphetamine abuse treatment: Predictors of treatment completion and comparison of two residential treatment programs. Drug and alcohol dependence, 201, 8-15.

Kipke, I., Brand, H., Geiger, B., Pfeiffer-Gerschel, T., \& Braun, B. (2015). Arbeitslosigkeit und Sucht-Epidemiologische und soziodemographische Daten aus der Deutschen Suchthilfestatistik 2007-2011. Sucht, 61(2), 81-94.

Kittirattanapaiboon, P., Srikosai, S., Wittayanookulluk, A. (2017). Methamphetamine use and dependence in vulnerable female populations. Curr Opin Psychiatry, 30(4), 247-252. https://doi.org/10.1097/YCO. 0000000000000335

Klee, H. (1997). A typology of amphetamine users in the United Kingdom. In H. Klee (Ed.), Amphetamine misuse: International perspectives on current trends (pp. 35-68). Harwood Academic Publishers.

Klein, M., Dyba, D. P. J., Moesgen, D., \& Urban, A. (2016). Crystal Meth und Familie-Zur Analyse der Lebenssituation und des Hilfebedarfs betroffener Kinder. Abschlussbericht an das Bundesministerium für Gesundheit. Katholische Hochschule Nordrhein-Westfalen.

Lamonica, A., \& Boeri, M. (2015). Risk behaviors among suburban women who use methamphetamine: Social harms and social solutions. Journal of Applied Social Science (Boulder), 9(2), 98-114. https://doi.org/10. $1177 / 1936724414525953$

Li, L. Z., \& Wang, S. (2021). Do work-family initiatives improve employee mental health? Longitudinal evidence from a nationally representative cohort. Journal of Affective Disorders, 297, 407-414. https://doi. org/10.1016/j.jad.2021.10.112

Liles, B. D., Newman, E., LaGasse, L. L., Derauf, C., Shah, R., Smith, L. M., . . Strauss, A. (2012). Perceived child behavior problems, parenting stress, and maternal depressive symptoms among prenatal methamphetamine users. Child Psychiatry \& Human Development, 43(6), 943-957.

Lin, S. K., Ball, D., Hsiao, C. C., Chiang, Y. L., Ree, S. C., \& Chen, C. K. (2004). Psychiatric comorbidity and gender differences of persons incarcerated for methamphetamine abuse in Taiwan. Psychiatry and Clinical Neurosciences, 58(2), 206-212.

Liu, D., Wang, Z., Chu, T., \& Chen, S. (2013). Gender difference in the characteristics of and high-risk behaviours among non-injecting heterosexual methamphetamine users in Qingdao, Shandong Province, China. BMC Public Health, 13, 30. https://doi.org/10.1186/1471-2458-13-30

Ludwig-Barron, N., Wagner, K. D., Syvertsen, J. L., Ewald, I. J., Patterson, T. L., Semple, S. J., \& Stockman, J. K. (2014). "When you get old like this ... you don't run those risks anymore": Influence of age on sexual risk behaviors and condom use attitudes among methamphetamine-using heterosexual women with a history of partner violence. Women's Health Issues, 24(6), 620-628. https://doi.org/10.1016/j.whi.2014.06. 007

MacMaster, S. A. (2013). Perceptions of need, service use, and barriers to service access among female methamphetamine users in rural Appalachia. Soc Work Public Health, 28(2), 109-118. https://doi.org/10.1080/ 19371918.2011.560820

Maglione, M., Chao, B., \& Anglin, D. (2000). Residential treatment of methamphetamine users: Correlates of drop-out from the California Alcohol and Drug Data System (CADDS), 1994-1997. Addiction Research, $8(1), 65-79$.

Malta, M., Varatharajan, T., Russell, C., Pang, M., Bonato, S., \& Fischer, B. (2019). Opioid-related treatment, interventions, and outcomes among incarcerated persons: A systematic review. PLoS Medicine, 16(12), e1003002.

Messina, N., Calhoun, S., \& Braithwaite, J. (2014). Trauma-informed treatment decreases posttraumatic stress disorder among women offenders. Journal of Trauma \& Dissociation, 15(1), 6-23. https://doi.org/10. 1080/15299732.2013.818609

Messina, N., Marinelli-Casey, P., Hillhouse, M., Rawson, R., Hunter, J., \& Ang, A. (2008). Childhood adverse events and methamphetamine use among men and women. J Psychoactive Drugs, Suppl, 5, 399-409.

Milin, S., Kleinau, C., Lüdorf, T., Lotzin, A., Degkwitz, P., Verthein, U., \& Schäfer, I. (2016). Konsummotive Bei Stimulanzienkonsum. Suchttherapie, 17(01), 17-21. 
Minozzi, S., Saulle, R., De Crescenzo, F., \& Amato, L. (2016). Psychosocial interventions for psychostimulant misuse. Cochrane Database of Systematic Reviews, 9(9), CD011866. https://doi.org/10.1002/14651858. CD011866

Mühlig, S., Haarig, F., Gusakova, A., \& Walter, C. (2015). Auswirkungen pränatalen Crystal Meth Konsums auf das Kind-eine systematische Literaturrecherche. Suchttherapie, 16(S 01), S_31_03. https://doi.org/10. 1055/s-0035-1557616

Murphy, G. C., \& Athanasou, J. A. (1999). The effect of unemployment on mental health. Journal of Occupational and Organizational Psychology, 72(1), 83-99.

National Institute on Drugs Abuse. (2020). "Substance Use in Women Research Report" by the National Institute on Drug Abuse. https://www.drugabuse.gov

Najavits, L. M., \& Hien, D. (2013). Helping vulnerable populations: A comprehensive review of the treatment outcome literature on substance use disorder and PTSD. Journal of Clinical Psychology, 69(5), 433-479.

Neumann, S., Franke, A. G., \& Soyka, M. (2017a). "Crystal Meth - Women's drug”? - What we currently know about the psychosocial contextual factors of the use of methamphetamine in women. Suchtmedizin, 19(4), 191-202.

Neumann, S., Soyka, M., \& Franke, A. G. (2017b). Bio-psycho-social characteristics and therapeutic aspects of methamphetamine-dependent women - gender-specific results of a systematic literature search. Psychotherapie, Psychosomatik und Medizinische Psychologie, 68(07), 281-289. https://doi.org/10. 1055/s-0043-115003

Niv, N., \& Hser, Y.-I. (2007). Women-only and mixed-gender drug abuse treatment programs: Service needs, utilization and outcomes. Drug and Alcohol Dependence, 87(2-3), 194-201.

Paulus, M. P., \& Stewart, J. L. (2020). Neurobiology, clinical presentation, and treatment of methamphetamine use disorder: A review. JAMA Psychiatry, 77(9), 959-966. https://doi.org/10.1001/jamapsychiatry.2020. 0246

Polcin, D. L., Buscemi, R., Nayak, M., Korcha, R., \& Galloway, G. (2012). Gender differences in psychiatric symptoms among methamphetamine dependent residents in sober living houses. Addictive Disorders \& Their Treatment, 11(2), 53-63. https://doi.org/10.1097/ADT.0b013e3182213ef1

Powelson, E., Lorvick, J., Lutnick, A., Wenger, L., Klausner, J., \& Kral, A. H. (2014). Unmet healthcare need among women who use methamphetamine in San Francisco. Substance Use and Misuse, 49(3), 243-252. https://doi.org/10.3109/10826084.2013.825919

Prendergast, M., Podus, D., Finney, J., Greenwell, L., \& Roll, J. (2006). Contingency management for treatment of substance use disorders: A meta-analysis. Addiction, 101(11), 1546-1560.

Proebstl, L., Kamp, F., Hager, L., Krause, D., Riebschläger, M., Neumann, S., . . Soyka, M. (2019). Associations between methamphetamine use, psychiatric comorbidities and treatment outcome in two inpatient rehabilitation centers. Psychiatry Res, 280, 112505.

Proebstl, L., Kamp, F., Hager, L., Krause, D., Riebschläger, M., Neumann, S., . . Koller, G. (2019). Associations between methamphetamine use, psychiatric comorbidities and treatment outcome in two inpatient rehabilitation centers. Psychiatry Res, 280, 112505.

Proebstl, L., Krause, D., Kamp, F., Hager, L., Manz, K., Schacht-Jablonowsky, M., . . Koller, G. (2019). Methamphetamine withdrawal and the restoration of cognitive functions-A study over a course of 6 months abstinence. Psychiatry Res, 281, 112599.

Querengässer, J., \& Traub, H.-J. (2020). Women in German forensic addiction treatment: Epidemiology and gender-related decision making in jurisdiction. International Journal of Law and Psychiatry, 70, 101567.

Rade, C. B., Desmarais, S. L., Van Dorn, R. A., Lutnick, A., Kral, A. H., \& Lorvick, J. (2015). Mental health correlates of drug treatment among women who use methamphetamine. The American Journal on Addictions, 24(7), 646-653. https://doi.org/10.1111/ajad.12279

Rawson, R. A., Gonzales, R., Obert, J. L., McCann, M. J., \& Brethen, P. (2005). Methamphetamine use among treatment-seeking adolescents in Southern California: participant characteristics and treatment response. Journal of Substance Abuse Treatment, 29(2), 67-74. https://doi.org/10.1016/j.jsat.2005.04.001

Rommel, N., Rohleder, N. H., Wagenpfeil, S., Haertel-Petri, R., \& Kesting, M. R. (2015). Evaluation of methamphetamine-associated socioeconomic status and addictive behaviors, and their impact on oral health. Addictive Behaviors, 50, 182-187.

Rusticus, S. A., \& Lovato, C. Y. (2014). Impact of sample size and variability on the power and type I error rates of equivalence tests: A simulation study. Practical Assessment, Research, and Evaluation, 19(1), 11.

Salo, R., Flower, K., Kielstein, A., Leamon, M. H., Nordahl, T. E., \& Galloway, G. P. (2011). Psychiatric comorbidity in methamphetamine dependence. Psychiatry Research, 186(2-3), 356-361.

Semple, S. J., Strathdee, S. A., Zians, J., \& Patterson, T. L. (2013). Correlates of drug dealing in female methamphetamine users. Journal of Urban Health, 90(3), 529-541. 
Semple, S. J., Zians, J., Strathdee, S. A., \& Patterson, T. L. (2007). Psychosocial and behavioral correlates of depressed mood among female methamphetamine users. Journal of Psychoactive Drugs, 39(sup4), 353-366.

Shen, W., Liu, Y., Li, L., Zhang, Y., \& Zhou, W. (2012). Negative moods correlate with craving in female methamphetamine users enrolled in compulsory detoxification. Substance Abuse Treatment, Prevention, and Policy, 7(1), 44.

Simpson, J. L., Grant, K. M., Daly, P. M., Kelley, S. G., Carlo, G., \& Bevins, R. A. (2016). Psychological burden and gender differences in methamphetamine-dependent individuals in treatment. Journal of Psychoactive Drugs, 48(4), 261-269. https://doi.org/10.1080/02791072.2016.1213470

Soyka, M., Koller, G., Proebstl, L., Kamp, F., Franke, A., Schmidt, P., Baumgärtner, G., Schacht-Jablonowsky, M., Sievert, A., Straif, M., \& Hamdorf, W. (2017). Prevalence and therapy of crystal methamphetamine dependence. Fortschritte der Neurologie-Psychiatrie, 85(2), 92-99. https://doi.org/10. 1055/s-0042-119862

Sun, W., Skara, S., Sun, P., Dent, C. W., \& Sussman, S. (2006). Project towards no drug abuse: Long-term substance use outcomes evaluation. Preventive Medicine, 42(3), 188-192.

United Nations Office on Drugs and Crime (UNODC). (2019). World drug report 2019: United Nations Publications.

Vik, P. W. (2007). Methamphetamine use by incarcerated women: Comorbid mood and anxiety problems. Women's Health Issues, 17(4), 256-263. https://doi.org/10.1016/j.whi.2006.12.004

Voss, M. W., Wadsworth, L. L., Birmingham, W., Merryman, M. B., Crabtree, L., Subasic, K., \& Hung, M. (2020). Health effects of late-career unemployment. Journal of Aging and Health, 32(1), 106-116.

Wittchen, H.-U., Wunderlich, U., Gruschwitz, S., \& Zaudig, M. (1997). SKID I. Strukturiertes Klinisches Interview für DSM-IV. Achse I: Psychische Störungen. Interviewheft und Beurteilungsheft. Eine deutschsprachige, erweiterte Bearb. d. amerikanischen Originalversion des SKID I.

Wouldes, T. A., LaGasse, L. L., Derauf, C., Newman, E., Shah, R., Smith, L. M., . . Lester, B. M. (2013). Co-morbidity of substance use disorder and psychopathology in women who use methamphetamine during pregnancy in the US and New Zealand. Drug Alcohol Depend, 127(1-3), 101-107. https://doi. org/10.1016/j.drugalcdep.2012.06.016

Zweben, J. E., Cohen, J. B., Christian, D., Galloway, G. P., Salinardi, M., Parent, D., . . . Project, M. T. (2004). Psychiatric symptoms in methamphetamine users. The American Journal on Addictions, 13(2), 181-190.

Publisher's Note Springer Nature remains neutral with regard to jurisdictional claims in published maps and institutional affiliations.

\section{Authors and Affiliations}

\section{Andreas G. Franke ${ }^{1,2}$. Stefanie Neumann ${ }^{2,3,4} \cdot$ Lisa Proebst| ${ }^{2,4}$ - Felicia Kamp ${ }^{2,4}$. Laura Hager ${ }^{2,4} \cdot$ Kirsi Manz $^{2,5}$. Daniela Krause ${ }^{2,4}$. Jochen Mutschler ${ }^{2,5} \cdot$ Gabi Koller $^{2,4}$. Michael Soyka ${ }^{2,4}$}

1 University of Applied Labour Studies, Seckenheimer Landstr. 16, D-68163 Mannheim, Germany

2 Private Hospital Meiringen, Willigen, 3860 Meiringen, Switzerland

3 European University of Applied Sciences, Werftstr. 5, 18057 Rostock, Germany

4 Department of Psychiatry and Psychotherapy, University Hospital Munich, Ludwig-MaximiliansUniversity Munich, Nußbaumstr. 7, 80336 Munich, Germany

5 Institute for Medical Information Processing, Biometry and Epidemiology (IBE), Faculty of Medicine, LMU Munich, Munich, Germany 